\title{
The importance of specialized sleep investigations in children with a suprasellar tumor
}

\author{
J. van Schaik ${ }^{1}$ (1) - S. Pillen ${ }^{2}$ R. R. L. van Litsenburg ${ }^{3,4} \cdot$ N. L. E. Vandenbussche ${ }^{2} \cdot$ J. M. de Bont ${ }^{3}$. \\ A. Y. N. Schouten-van Meeteren ${ }^{3}$ H. M. van Santen ${ }^{1,3}$
}

Published online: 20 July 2020

(c) The Author(s) 2020

\begin{abstract}
Purpose Disruption of sleep has great impact on quality of life. In children with a suprasellar tumor and hypothalamicpituitary dysfunction, the circadian rhythm may be disturbed causing sleep problems. However, also other factors may influence sleep. Awareness of these different etiologies and careful history taking with appropriate additional diagnostics will aid in restoring sleep quality.

Methods We present the workup of 4 cases with a suprasellar tumor and disturbances of sleep initiation, sleep maintenance, and daytime sleepiness. In parallel, we developed a flowchart, to aid clinicians in the diagnostics of sleep problems in children after treatment for a (supra) sellar brain tumor.

Results All four patients, known with hypopituitarism, presented with sleep complaints and increased daytime sleepiness. In all four, the cause of sleep problems showed to be different. In the first case, sleep evaluation revealed a severe obstructive sleep apnea, whereupon nocturnal ventilation was started. The second case revealed poor sleep hygiene in combination with an obsessive compulsive disorder. Sleep hygiene was addressed and psychiatric consultation was offered. Dexamphetamine treatment was started to reduce her obsessive compulsive complaints. The third case showed a delayed sleep phase syndrome, which improved by educational support. The fourth case revealed a secondary organic hypersomnia for which modafinil treatment was started.

Conclusion Sleep disturbances in children with hypopituitarism due to a (supra) sellar tumor can have different entities which require specific therapy. Awareness of these different entities is important to enable appropriate counseling. Referral to an expertise sleep center may be advised, if standard educational support is insufficient.
\end{abstract}

Keyword Childhood brain tumor survivors $\cdot$ Suprasellar tumors $\cdot$ Sleep disturbances $\cdot$ Increased daytime sleepiness $\cdot$ Sleep investigation

\section{Abbreviations}

CBTS Childhood Brain Tumor Survivor

LHA Lateral Hypothalamic Area

J. van Schaik

j.vanschaik-3@umcutrecht.nl

1 Department of Pediatric Endocrinology, Wilhelmina Children Hospital, University Medical Center Utrecht, Lundlaan 6, Utrecht 3584 EA, The Netherlands

2 Department of Sleep Medicine, Kempenhaeghe Expertise Center for Epileptology, Sleep Medicine and Neurocognition, Heeze, The Netherlands

3 Princess Máxima Center for Pediatric Oncology, Utrecht, The Netherlands

4 Emma Children's Hospital, Amsterdam UMC, Vrije Universiteit Amsterdam, Pediatric Oncology Cancer Center Amsterdam, Amsterdam, The Netherlands

$\begin{array}{ll}\text { BMI } & \text { Body Mass Index } \\ \text { PSG } & \text { Polysomnography } \\ \text { Gray } & \text { Gy } \\ \text { ESS } & \text { Epworth Sleepiness score } \\ \text { SOREMP } & \text { Sleep-onset REM period } \\ \text { HP } & \text { Hypothalamic-pituitary } \\ \text { SCN } & \text { Suprachiasmatic nucleus } \\ \text { MSLT } & \text { Multiple Sleep Latency Test }\end{array}$

\section{Introduction}

Due to increased survival rates for children with a CNS tumor, the late effects of the tumor and its treatment are becoming more visible and more important [1]. Childhood brain tumor survivors (CBTS) often report a low quality of 
life and an important factor that may influence the degree of quality of life is their quality of sleep [2].

Sleep is a complex neurophysiologic process. The suprachiasmatic nuclei are key regulators of the circadian rhythm, controlling sleep and wakefulness [3, 4]. Melatonin, excreted by the pineal gland in the dark, greatly influences this circadian rhythm (Fig. 1a) [4]. In children with a (supra) sellar tumor the circadian rhythm may be disturbed due to a distorted melatonin excretion or a distorted response to melatonin [5-7]. In addition to the suprachiasmatic nuclei, the ventrolateral preoptic nucleus (VLPO) together with the lateral hypothalamus area (LHA) (sleep-promoting), and monoaminergic cell groups (MCG) (the arousal system) also regulate sleep [8]. These sleep-promoting pathways and arousal pathways can mutually influence each other by the "flip-flop" switch (Fig. 1b) [9]. This interaction rapidly promotes the transition between waking and sleeping. Damage to the VLPO results in insomnia and damage to the LHA results in both sleep disruption as well as daytime hypersomnolence [10-13].

It is well known that patients with a (supra) sellar tumor are prone to develop sleep problems or daytime sleepiness $[14,15]$. While the physical damage caused by the tumor or its treatment is a probable causal mechanism, other risk

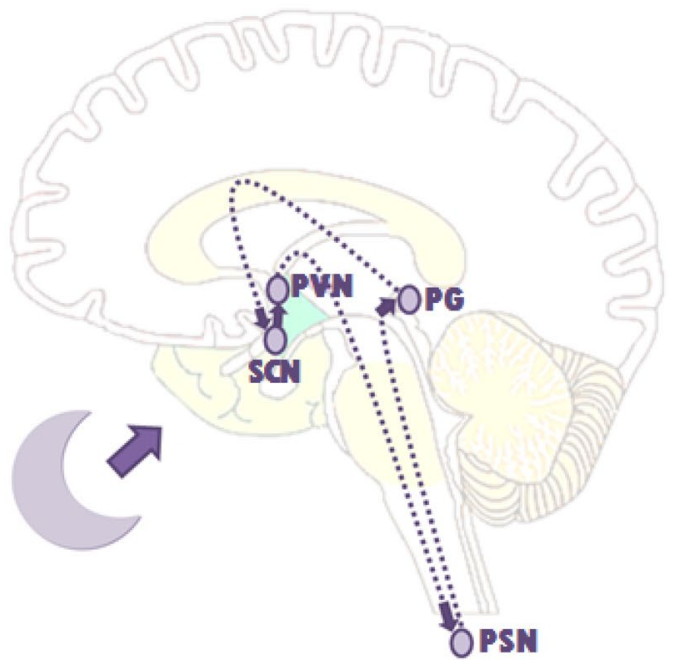

Fig. 1 Schematic drawing of the circadian rhythm and arousal system involved in the flip-flop switch. a A schematic drawing of the suprachiasmatic nuclei $(\mathrm{SCN})$ controlling the circadian rhythm during sleep. Through activation of the SCN via the axons of retinal ganglion cells running in the optic nerves (forming a retino-hypotalamic tract), the SCN sends a signal to the paraventricular nuclei (PVN) and preganglionic sympathetic neurons (PSN), which in their turn activate the pineal gland $(\mathrm{PG})$ to produce melatonin. b A schematic drawing to show the basic route of the ventrolateral preoptic nucleus (VLPO) to the main elements of the ascending arousal system, involved in the flip-flop switch. The arousal system consist of monoaminergic cell groups (MCG) such as the tuberomammillary nucleus (TMN), the raphe nuclei $(\mathrm{RN})$ and the locus coeruleus (LC). VLPO neurons also factors, such as psychological, behavioral, and social environmental should also be considered. Parenting strategies that include regular bedtime routines and consistent limit setting are required to develop healthy sleep habits, but may be a challenge to parents of a child with a life-threatening or chronic disease [16, 17].

There are currently no guidelines for assessment of sleep disturbances in this group. Early referral to a specialized sleep clinic may reveal the etiology of the sleep disturbance and will give direction to the proper treatment. The following cases illustrate the importance of specialized diagnostics to distinguish the different etiologies of sleep disturbances in children with a suprasellar tumor enabling proper treatment.

\section{Case 1}

A 13 year-old girl, presented with frequent headaches during day and night, inability to fall asleep, difficulty maintaining sleep, and daytime sleepiness. She was diagnosed with craniopharyngioma at the age of six and underwent gross total resection. Magnetic Resonance Imaging (MRI) of the brain at follow-up showed absence of the pituitary stalk and damage of the anterior and posterior hypothalamic region with atrophic mammillary bodies, scored by

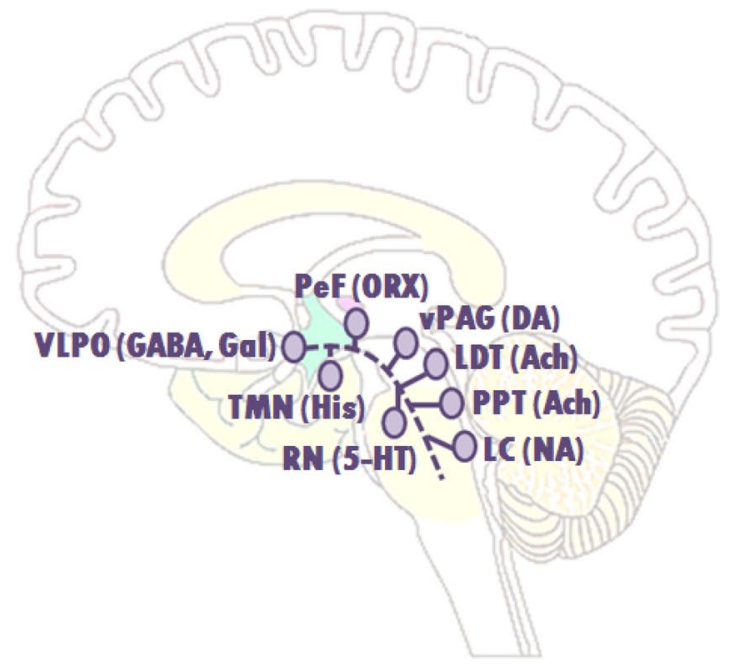

stimulate the neurons in the lateral hypothalamus, such as the perifornical (PeF) and orexin (ORX) neurons, and the cholinergic (ACh) cell groups; the pedunculopontine (PPT) and laterodorsal tegmental nuclei (LDT). During a wakeful state, the MNG inhibit the VLPO neurons, thereby activating the arousal system trough the MNG, and that of the ORX neurons and the PPT and LDT. During sleep, the firing of the VLPO neurons suppress the MNG. This also allows it to inhibit the orexin neurons, further preventing monoaminergic activation that might interrupt sleep. The direct inhibition between both groups, the VLPO and the monoaminergic cell groups, forms the flipflop switch. 5-HT, serotonin; GABA, $\gamma$-aminobutyric acid; gal, galanin; NA, noradrenaline; His, histamine 
the neuroradiologist as grade II, according to the Muller grading for hypothalamic damage [18]. After surgery, she developed panhypopituitarism and morbid obesity (Body Mass Index (BMI) Standard Deviation Score (SDS) of 5.1). Patient had been adequately hormonally supplemented for all pituitary deficiencies and used dextroamphetamine for her hypothalamic obesity. Her medical history further contained repeated surgery of her knees due to varus position. Due to her knee problems together with her morbid obesity, she was partially wheel chair bound.

Sleep history revealed long screen time before and during bed time, difficulty in sleep initiation and maintenance, and worrying during the night. There were no complaints of snoring, but a moaning sound was frequently heard by parents in the night.

Polysomnography (PSG) with capnography revealed a normal sleep latency with a recognizable cyclic sleep structure. Patient had a continuous tachypnea of 35- 40 times per minute, with frequently a typical breathing pattern in REM sleep, starting with a deep sigh following a long exhale in combination with a moaning sound, indicative of catathrenia. She had obstructive sleep apnea, with an apnea-hypopnea index of 19.4 (normal in children $<1 / \mathrm{h}$ ), and an oxygenation-desaturation index ( $\geq 3 \%$ ) of 33.8 ( $>10$ indicative for moderate to severe obstructive sleep apnea). Lowest oxygen level was $63 \%$. Her carbon dioxide was normal during the day, but increased upon awakening $(49.4 \mathrm{mmHg}$ ) (Table 1). The melatonin test showed no increase in melatonin concentration (Table 2). Patient was diagnosed with obstructive sleep apnea, sleep related hypoventilation and catathrenia according to the ICSD-3 criteria. Patient was referred for nocturnal home bi-level ventilation, with a inspiratory pressure support of 18 and external pressure support of 6 , after which she experienced less symptoms of insomnia, less headaches and less daytime sleepiness.

\section{Case 2}

A 12 year-old girl with complaints of waking up earlier than desired and daytime sleepiness was referred for sleep evaluation. She had been diagnosed with craniopharyngioma at age five. Patient underwent subtotal resection, complicated by a subdural hematoma and meningitis. After surgery, patient received cranial irradiation. MRI of the brain at follow-up, after surgery and irradiation, showed severe anterior and posterior hypothalamic damage behind the mammillary bodies, grade II according to the Muller grading of hypothalamic damage. She experienced rapid weight gain (BMI SDS 4.3) with obsessive compulsive mood disorder. Medical history showed no other relevant comorbidities. Patient received adequate hormonal supplementation for all pituitary deficiencies.
During the night, the mother occasionally heard snoring and apneas. The girl experienced early awakenings (4.00 a.m.) with a strong urge to search for food. This food seeking behavior was present both day and night. She was aware of her behavior, but could not control this strong urge. Sleepiness was present in the morning and evening, which resulted in falling asleep in public places, with extreme difficulty to be woken up.

Both the PSG with capnography and melatonin test (Tables 1 and 2) showed normal results, with no indication for a obstructive sleep apnea syndrome or a circadian rhythm disorder. Based on her sleep wake calendar and history taking, she met the criteria of the ICSD-3 for a chronic insomnia disorder, in which her obsessive compulsive disorder and strong urge for food in combination with poor sleep hygiene were the most important perpetuating factors. For the prominent obsessive compulsive behavior, she was referred for psychiatric consultation. Dextroamphetamine was started to reduce her obsessive compulsive complaints, also aiming to positively affect her hypothalamic obesity.

\section{Case 3}

A 16 year-old girl with complaints of difficulty initiating sleep and daytime sleepiness was referred for sleep evaluation. She was treated at age 8 years for suprasellar germinoma with chemotherapy, neurosurgery, and radiotherapy. MRI of the brain at follow-up showed no hypothalamic damage, only damage in the sellar region, grade 0 according to the Muller grading of hypothalamic damage. She had been diagnosed with panhypopituitarism and obesity. Patient had been adequately hormonally supplemented for all pituitary deficiencies. Medical history showed no other relevant comorbidities.

Her sleep history showed relatively long screen time before sleeping and irregular and long time in bed (between 11 and $14 \mathrm{~h}$ ), but with a normal sleep duration of over $8 \mathrm{~h}$ (Table 1). She had no complaints of waking up during the night, snoring, dry mouth, or nycturia. She frequently had headaches during the day.

A dim light melatonin onset test was performed and showed a normal but late increase of melatonin (Table 2). She met the ISCD-3 criteria for a delayed sleep phase syndrome diagnosis together with an inadequate sleep hygiene. She received education for improving her sleep hygiene, with special attention to a regular sleep wake rhythm, less time in bed, and avoidance of screen time before going to bed. With this advice, the sleep wake rhythm normalized and daytime complaints disappeared. 
Table 1 Sleep evaluation data of all four cases

\begin{tabular}{|c|c|c|c|c|}
\hline Subjective sleep data* & Case 1 & Case 2 & Case 3 & Case 4 \\
\hline TIB & $10 \mathrm{~h} 17 \mathrm{~min}$ & $9 \mathrm{~h} 47 \mathrm{~min}$ & $11 \mathrm{~h} 49 \mathrm{~min}$ & 8 h 39 min \\
\hline Bed time & 8.32 p.m & 9.08 p.m & 9.26 p.m & 9.47 p.m \\
\hline Rise time & 6.49 a.m & 6.55 a.m & 9.15 a.m & 6.26 a.m \\
\hline TST & $5 \mathrm{~h} 54 \mathrm{~min}$ & $6 \mathrm{~h} 58 \mathrm{~min}$ & $8 \mathrm{~h} 17 \mathrm{~min}$ & $7 \mathrm{~h} 37 \mathrm{~min}$ \\
\hline SOL & $1 \mathrm{~h} 49 \mathrm{~min}$ & $1 \mathrm{~h} 12 \mathrm{~min}$ & $1 \mathrm{~h} 14 \mathrm{~min}$ & $48 \mathrm{~min}$ \\
\hline WASO & $2 \mathrm{~h} 17 \mathrm{~min}$ & $20 \mathrm{~min}$ & $41 \mathrm{~min}$ & $1 \mathrm{~h} 53 \mathrm{~min}$ \\
\hline WASF & $24 \min$ & $1 \mathrm{~h} 28 \mathrm{~min}$ & $1 \mathrm{~h} 2 \mathrm{~min}$ & $14 \min$ \\
\hline \multicolumn{5}{|l|}{ Questionnaire } \\
\hline ESS & 12 & - & 11 & 23 \\
\hline MSLT & - & - & - & $2.7 \mathrm{~min}, 1 \mathrm{SOREMP}$ \\
\hline Polysomnography** & & & - & \\
\hline TIB & $487.0 \mathrm{~min}$ & $573.0 \mathrm{~min}$ & & $737.0 \mathrm{~min}$ \\
\hline TST & $463.5 \mathrm{~min}$ & $500 \mathrm{~min}$ & & $547.5 \mathrm{~min}$ \\
\hline SOL & $1.0 \mathrm{~min}$ & $4.5 \mathrm{~min}$ & & $\begin{array}{l}0 \text { min, time until } \\
\text { first REM } 369 \text { min }\end{array}$ \\
\hline WASO & $22.5 \mathrm{~min}$ & $68.5 \mathrm{~min}$ & & $18.5 \mathrm{~min}$ \\
\hline $\mathrm{SE}$ & $95.2 \%$ & $87.3 \%$ & & $74.3 \%$ \\
\hline \multicolumn{5}{|l|}{ Sleep stages } \\
\hline REM & $3.8 \%$ & $17.0 \%$ & & $29.8 \%$ \\
\hline NREM 3 & $48.8 \%$ & $17.4 \%$ & & $11.7 \%$ \\
\hline AHI & 19.4, obstr & 1.1 , obs \& centr & & 2.6, obstr \& centr \\
\hline AI & 0.0 & 0.1 & & 0.3 \\
\hline PLMI & 0.0 & 9.0 & & 5.8 \\
\hline ODI $(3 \%)$ & 33.8 & 2.2 & & 1.3 \\
\hline ODI $(4 \%)$ & 11.1 & 1.2 & & 0.5 \\
\hline Mean $\mathrm{CO} 2^{\wedge}$ level: & 43.0 & 46.0 & & - \\
\hline Highest CO2 REM: & 46.2 & 47.5 & & \\
\hline Highest CO2 NREM: & 47.2 & 47.5 & & \\
\hline Blood gas $^{\wedge}$ analysis after sleep: & $\begin{array}{c}7 \text { a.m.: pH 7.35, pCO2 49.3, HCO3 26.5, BE } 0.911 \\
\text { a.m.: pH 7.42, PCO2 36.8, HCO3 23.2, BE - } 0.5\end{array}$ & & & \\
\hline Mean O2 level: & $95 \%$ & $94 \%$ & & $98 \%$ \\
\hline Lowest $\mathrm{O} 2$ level: & $63 \%$ & $86 \%$ & & $91 \%$ \\
\hline Time below 90\%: & $5.7 \mathrm{~min}$ & $9.5 \mathrm{~min}$ & & $0 \mathrm{~min}$ \\
\hline
\end{tabular}

TIB time in bed, TST total sleep time, SOL sleep onset latency, WASO Wake after sleep onset, WASF wake after sleep offset, ESS Epworth sleepiness scale, MSLT Multiple sleep latency test, SOREMP sleep onset REMsleep period, SE sleep efficiency, REM rapid eye movement sleep, $N R E M$ non rapid eye movement sleep, $A H I$ apnea hypopnea index, obstr obstructive apnea, centr central apnea, $A I$ apnea index, $P L M I$ periodic limb movements of sleep, $O D I$ oxygen desaturation index, $\mathrm{CO} 2$ carbon dioxide, $\mathrm{HCO} 3$ Bicarbonate, $\mathrm{BE}$ Base excess

$-=$ data is not available or test is not performed

*Subjective sleep data consisted of data of 1 week graphical sleep wake diary, data of case 4 consisted of actigraphy data due to incorrect sleepwake diary

** The polysomnography consisted of an all night supervised video polysomnography performed according to the AASM (American academy of sleep medicine) criteria version 2.6, including: (1) 8 EEG- channels (F4-M1, C4-M1, O2-M1, with back-up F3-M2, C3-M2 and O1-M2); (2) 2 electroculographic channels; and (3) 4 surface electromyographic channels: 2 from the mentalis, one from the right anterior tibialis and one from the left anterior tibialis in lower limbs; and (4) 7 channels to monitor respiratory function: 1 for oximetry, 1 for transcutaneous carbondioxide 2 for oro-nasal airflow using a thermistor and nasal-cannula, 2 to record thoraco-abdominal movements by inductance plethysmography, and a microphone at the suprasternal notch to detect snoring. Transcutaneous carbon dioxide measurement was calibrated with capillary blood gas samples preceding the PSG night and at awakening. Sleep stages were visually scored for 30 -s epochs according to the guidelines of the American Academy of Sleep Medicine (AASM) version 2.6. Scoring was performed by an experienced sleep technologist and later reviewed by an accredited sleep specialist

${ }^{\wedge} \mathrm{CO} 2$ presented as $\mathrm{mmHg}$

$\wedge^{\wedge} \mathrm{Blood}$ gas presented as $\mathrm{pH}, \mathrm{CO} 2=\mathrm{mm} \mathrm{Hg}, \mathrm{O} 2=\mathrm{mm} \mathrm{Hg}, \mathrm{HCO} 3=\mathrm{mmol} / \mathrm{L}, \mathrm{BE}=\mathrm{mmol} / \mathrm{L}$ 
Table 2 Measured melatonin values of four cases

\begin{tabular}{lllll}
\hline Time & Case 1 & Case 2 & Case 3 & Case 4 \\
\hline $12.00 \mathrm{pm}$ & 0.9 & & & \\
$6.00 \mathrm{pm}$ & $<0.5$ & $<0.5$ & & 0.8 \\
$7.00 \mathrm{pm}$ & & 1.7 & 0.5 & 0.9 \\
$8.00 \mathrm{pm}$ & 1.6 & $6.3($ DLMO 7.30$)$ & 0.5 & $<0.5$ \\
$9.00 \mathrm{pm}$ & $<0.5$ & $<0.5^{\wedge}$ & 1.0 & $<0.5$ \\
$10.00 \mathrm{pm}$ & & $4.6($ DLMO 10.50$)$ & $1.1($ DLMO 10.13) \\
$11.00 \mathrm{pm}$ & & 6.5 & 28.01 \\
$12.00 \mathrm{pm}$ & & & & 1.2 \\
$1.30 \mathrm{am}$ & $*$ & 4.8 & & $>50.0^{\wedge}$ \\
$6.00 \mathrm{am}$ & & 8.0 & & 2.2 \\
$7.00 \mathrm{am}$ & $*$ & & & \\
$8.00 \mathrm{am}$ & & & & \\
$9.00 \mathrm{am}$ & $<0.5$ & & & \\
\hline
\end{tabular}

Values are represented as $\mathrm{pg} / \mathrm{ml}$ measured in saliva

*Not enough material for detection

${ }^{\wedge}$ Suspected measurement error due to food intake (breakfast)

DLMO Dim Light Melatonin Onset (the estimated time at which salivary melatonin reaches $4 \mathrm{pg} / \mathrm{ml}$ )

\section{Case 4}

A 16 year old boy presented with complaints of difficulty initiating sleep and maintaining sleep, waking up earlier than desired, and daytime sleepiness. He had been diagnosed with pilocytic astrocytoma in the suprasellar region and neurofibromatosis type I at age 7 . Therapy consisted of subsequent episodes of neurosurgery, chemotherapy, and irradiation. MRI of the brain at follow-up, after neurosurgery, chemotherapy, and irradiation, showed abnormalities due to MoyaMoya syndrome and neurofibromatosis, plus anterior and posterior hypothalamic damage behind the mammillary bodies (grade II Muller et al.) with residual cystic mass in the suprasellar region. He developed panhypopituitarism in combination with the syndrome of inappropriate antidiuretic hormone (SIADH) and weight gain. Due to Moyamoya syndrome, patient also developed transient ischemic attacks. Patient had been adequately hormonally supplemented for all pituitary deficiencies. Medical history showed no other relevant comorbidities.

Sleep history showed insomnia during the night consisting of sleep onset problems, prolonged night time awaking of several hours, and early morning awakening. He frequently left bed during the night, to secretly eat and drink. This food seeking behavior was present both day and night. Patient was aware of this behavior, but could not control this strong urge. He also tended to secretly watch TV when awake in the night. Parents had already received guidance by behavioral therapists to alter this behavior, but still had difficulties in addressing this behavior, because they were often not aware of his night time awakenings. During the day, he suffered from severe hypersomnolence with falling asleep at school, when watching TV or even during meals, resulting a very high Epworth sleepiness scale score of 23 out of 24 (normal $<11$ ).

Actigraphy confirmed insomnia with prolonged sleep onset, early morning awakening, and frequent naps during the day. PSG showed a normal cyclic sleep structure, with normal sleep duration of more than $9 \mathrm{~h}$. The multiple sleep latency test showed a short sleep latency of $2.7 \mathrm{~min}$ (normal $>8 \mathrm{~min}$ ) and one sleep-onset REM period (SOREMP) (Table 1). A mildly delayed increase of melatonin concentration in the evening was seen (Table 2). These mixed results made it difficult to make a formal ICSD-3 diagnosis. Narcolepsy was ruled out based on the MSLT results in combination with absence of other narcolepsy symptoms, but secondary organic hypersomnia was suspected based on the severe daytime sleepiness. Treatment was based on a multidisciplinary symptom-based approach. Behavioral therapy was started to address the behavior of going out of bed in the night and improving sleep hygiene. Additionally, pharmacological treatment with modafinil was started. These measures improved both his daytime functioning as well stabilized his sleep rhythm with less night time awakening.

\section{Discussion}

Sleep disturbances in children surviving a (supra) sellar tumor are common [19]. These cases illustrate that, also in children with tumors in this location, extended sleep evaluation may reveal different etiologies enabling individual treatment. The fact that sleep disturbances are not only associated with decreased quality of life, but also with obesity, makes 
it of special interest in this patient group, as they often also cope with (hypothalamic) obesity [20-24]. For these reasons, sleep is one of the important clinical domains on which a child surviving a suprasellar tumor should be evaluated. When the sleep disturbance is adequately addressed, BMI and quality of life during the day and night may be improved [25].

Symptoms of a sleep disturbance in children with a tumor in the suprasellar region that have been frequently described in literature are difficulty initiating sleep, maintaining sleep, waking up earlier than desired, but also increased daytime sleepiness [7, 19, 26]. Increased daytime sleepiness can be a result of disturbed circadian rhythm, reduced sleep, or of insufficient hormonal substitution. Sleep and the circadian rhythm is mainly regulated by hypothalamic structures, such as the suprachiasmatic region involved in the melatonin secretion, the median and ventrolateral preoptic areas involved in the flip-flop switch model, and the lateral/ posterior nuclei, important for regulating wakefulness [3, 8, 27]. Destruction of these structures, either due to the tumor or its treatment, thus play an important role in the etiology of sleep disturbances in children surviving a tumor in the hypothalamic-pituitary (HP) region [10, 11, 13, 28-30].

Many children surviving tumors in the HP region suffer from obesity [31]. As obstructive sleep apnea is very common in obese patients (upon 60\%), children with hypothalamic obesity and complaints of fatigue or daytime sleepiness should be evaluated for the presence of obstructive sleep apnea. The complications of sleep apnea can be very severe (e.g. cardiovascular and metabolic, growth retardation and reduced quality of life) [30, 32, 33].

Next to sleep apnea, the melatonin production may be altered due to damage of the SCN. Decreased nocturnal melatonin levels have been associated with increased daytime sleepiness, higher BMI, and hypothalamic tumor diagnosis [34]. In 10 adult obese patients after treatment for childhood craniopharyngioma, treatment with melatonin was found to be successful to decrease daytime sleepiness. Melatonin treatment may be useful in decreasing sleep onset latency and improving sleep total time, however some question its safety for use in children given the broad (side) effects on multiple developing systems and it fails to target long term maintaining factors that cause sleep disruption to persist [35, 36]. Medication such as melatonin should therefore only be considered after extended additional diagnostics in a specialized sleep clinic, in agreement with a somnologist.

Secondary narcolepsy was considered in the fourth case, which has been related to the flip-flop switch [37]. In a study by Muller et al., seven of ten suprasellar tumor patients were found to fulfill the criteria for secondary narcolepsy [34]. Narcolepsy in patients with hypothalamic lesions is most likely due to direct injury to the orexin-expressing neurons (located in the lateral hypothalamus), which are involved in the flip-flop switch [38, 39]. Although case four did not meet the criteria for narcolepsy, his MSLT was very short, fulfilling the criteria of hypersomnia due to a medical condition. This short MSLT time can be classified as severe sleepiness and may be a consequence of hypothalamic damage resulting in disturbance of the flip-flop switch [40]. Treatments given for narcolepsy, such as modafinil, dexamphetamine, methylphenidate, and other stimulants may, in these situations, be effective [41, 42].

Last, but not least important, psychological or psychiatric complaints, poor sleep hygiene, and inappropriate light exposure may cause sleep disturbance resulting in insomnia and increased daytime sleepiness. Worrying thoughts, anxiety, depression, and obsessive compulsive mood disorder, which is more frequently seen in children with hypothalamic damage, may severely influence sleep quality [43]. This warrants a broad and multidisciplinary approach when dealing with sleep problems in these children. Further, particularly in adolescents, delayed sleep phase disorder is common due to lengthen of the circadian rhythm, as the child becomes more social. Inadequate sleep hygiene includes those habits that enhance wakefulness and interrupt the sleep period, leading to a decrease in the quality of sleep and increased daytime sleepiness. Examples of these habits include engaging in stimulating activities near bedtime, using the bed for activities not related to sleep, inconsistent bedtimes, and inappropriate napping [44]. Treatment of these disorders is primarily educational, with strict sleep structure and restriction of screen time [45]. Restriction in screen time will lead to more mobility and more social behavior [46]. Especially, mobility and physical activity during the day can improve sleep quality drastically [47-49].

Of our four cases, all of them showed inadequate sleep hygiene, which needed to be addressed. Providing knowledge and guidance to parents about adequate sleep hygiene and structure for their child, during and after cancer treatment should therefore be considered as standard care and may play an important role in prevention of sleep disturbances. To aid in diagnostics of sleep problems in children after treatment for a (supra) sellar brain tumor, a flowchart is proposed (Fig. 2).

\section{Conclusion}

Children surviving a (supra) sellar tumor may present with sleep disturbances due to variable causes. Education of sleep hygiene and bedtime structure is important for all. Referral to an expertise sleep center may help to distinguish the different causes of sleep problems in this specific patient group and enable adequate intervention. 


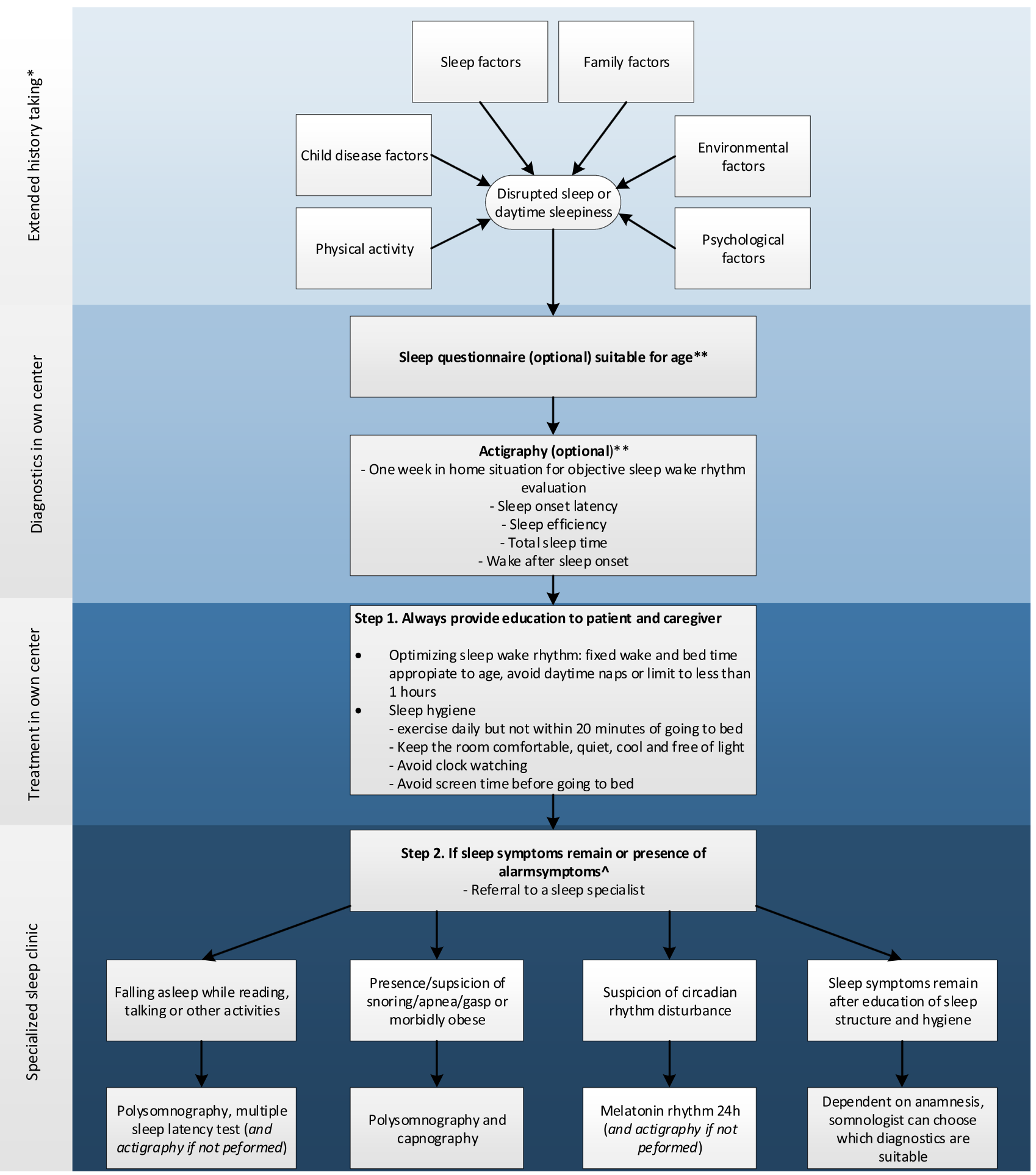

Fig. 2 Proposed additional diagnostics regarding sleep disturbances in children with a brain tumor. *Extended history taking consists of: 1. Sleep factors: sleep wake pattern (sleep schedule, bedtime routine, screen time), total sleep time, nycturia, wake after sleep onset time, sleep symptoms (snoring, sleepwalking), daytime symptoms (morning headache, daytime sleepiness, naps). 2. Child disease factors: medical history, current treatment, pain, side-effect of treatment, medication. 3. Psychological factors: stress factors, anxiety, trauma, depression. 4. Family factors: parenting styles, parenting belief, attitude, siblings. 5. Environmental factors: sleep environment, sleep position. 6. Physical activity: transport, sport, school. **For examples and additional information of suitable sleep questionnaires or actigraphy, see: Table 1 https://doi.org/10.1002/pon.5242 [50]. ^Alarm symptoms: falling a sleep during activities or snoring, apnea, or gasping during sleep 
Author's Contribution Drs. JvanS conceptualized and designed the study, contributed to the acquisition, analysis and interpretation of the data, drafted the initial manuscript, and reviewed and revised the manuscript. Dr. SP and Dr. RvanL conceptualized and designed the study, contributed to the acquisition, analysis and interpretation of the data, and reviewed and revised the manuscript. Drs. NV, Dr. JB, and Dr. NS-vanM substantial contributed to the analysis and interpretation of the data and reviewed and revised the manuscript. Dr. HvanS conceptualized and designed the study, coordinated and supervised data collection, and critically reviewed the manuscript for important intellectual content. All authors approved the final manuscript as submitted and agree to be accountable for all aspects of the work.

Funding No funding was secured for this study.

Data availability Deidentified individual participant data will not be made available.

\section{Compliance with ethical standards}

Conflict of interest The authors declare that they have no conflict of interest.

Ethical approval All procedures performed in studies involving human participants were in accordance with the ethical standards of the institutional and national research committee and with the 1964 Helsinki declaration and its later amendments or comparable ethical standards.

Informed consent Informed consent was obtained from all individual participants included in the study.

Consent for publication The patients had consented to the submission of their case report for submission to the journal.

Open Access This article is licensed under a Creative Commons Attribution 4.0 International License, which permits use, sharing, adaptation, distribution and reproduction in any medium or format, as long as you give appropriate credit to the original author(s) and the source, provide a link to the Creative Commons licence, and indicate if changes were made. The images or other third party material in this article are included in the article's Creative Commons licence, unless indicated otherwise in a credit line to the material. If material is not included in the article's Creative Commons licence and your intended use is not permitted by statutory regulation or exceeds the permitted use, you will need to obtain permission directly from the copyright holder. To view a copy of this licence, visit http://creativecommons.org/licenses/by/4.0/.

\section{References}

1. Roddy E, Mueller S (2016) Late effects of treatment of pediatric central nervous system tumors. J Child Neurol 31(2):237-254. https://doi.org/10.1177/0883073815587944

2. Macartney G, VanDenKerkhof E, Harrison MB, Stacey D (2014) Symptom experience and quality of life in pediatric brain tumor survivors: a cross-sectional study. J Pain Symptom Manage 48(5):957-967. https://doi.org/10.1016/j.jpainsymma n.2013.12.243

3. Saper CB, Scammell TE, Lu J (2005) Hypothalamic regulation of sleep and circadian rhythms. Nature 437(7063):1257-1263. https ://doi.org/10.1038/nature04284
4. Cajochen C, Krauchi K, Wirz-Justice A (2003) Role of melatonin in the regulation of human circadian rhythms and sleep. J Neuroendocrinol 15(4):432-437

5. Foschi M, Sambati L, Zoli M, Pierangeli G, Cecere A, Mignani F, Barletta G, Sturiale C, Faustini-Fustini M, Milanese L, Cortelli P, Mazzatenta D, Provini F (2017) Site and type of craniopharyngiomas impact differently on 24-hour circadian rhythms and surgical outcome. A Neurophysiol Evaluation Auton Neurosci 208:126-130. https://doi.org/10.1016/j.autneu.2017.08.006

6. Gapstur R, Gross CR, Ness K (2009) Factors associated with sleep-wake disturbances in child and adult survivors of pediatric brain tumors: a review. Oncol Nurs Forum 36(6):723-731. https ://doi.org/10.1188/09.ONF.723-731

7. Muller HL, Handwerker G, Wollny B, Faldum A, Sorensen N (2002) Melatonin secretion and increased daytime sleepiness in childhood craniopharyngioma patients. J Clin Endocrinol Metab 87(8):3993-3996. https://doi.org/10.1210/jcem.87.8.8751

8. Gallopin T, Fort P, Eggermann E, Cauli B, Luppi PH, Rossier J, Audinat E, Muhlethaler M, Serafin M (2000) Identification of sleep-promoting neurons in vitro. Nature 404(6781):992-995. https://doi.org/10.1038/35010109

9. Donlea JM, Alam MN, Szymusiak R (2017) Neuronal substrates of sleep homeostasis; lessons from flies, rats and mice. Curr Opin Neurobiol 44:228-235. https://doi.org/10.1016/j. conb.2017.05.003

10. Jurkowlaniec E, Trojniar W, Tokarski J (1994) Daily pattern of EEG activity in rats with lateral hypothalamic lesions. J Physiol Pharmacol 45(3):399-411

11. Lu J, Greco MA, Shiromani P, Saper CB (2000) Effect of lesions of the ventrolateral preoptic nucleus on NREM and REM sleep. J Neurosci 20(10):3830-3842

12. Ono D, Yamanaka A (2017) Hypothalamic regulation of the sleep/wake cycle. Neurosci Res 118:74-81. https://doi. org/10.1016/j.neures.2017.03.013

13. Marcus CL, Trescher WH, Halbower AC, Lutz J (2002) Secondary narcolepsy in children with brain tumors. Sleep 25(4):435-439

14. Anderson NE (2003) Late complications in childhood central nervous system tumour survivors. Curr Opin Neurol 16(6):677683. https://doi.org/10.1097/01.wco.0000102623.38669.e5

15. Rosen GM, Bendel AE, Neglia JP, Moertel CL, Mahowald M (2003) Sleep in children with neoplasms of the central nervous system: case review of 14 children. Pediatrics 112(1 Pt 1):e46-54. https://doi.org/10.1542/peds.112.1.e46

16. McCarthy MC, Bastiani J, Williams LK (2016) Are parenting behaviors associated with child sleep problems during treatment for acute lymphoblastic leukemia? Cancer Med 5(7):1473-1480. https://doi.org/10.1002/cam4.727

17. Long KA, Keeley L, Reiter-Purtill J, Vannatta K, Gerhardt CA, Noll RB (2014) Child-rearing in the context of childhood cancer: perspectives of parents and professionals. Pediatr Blood Cancer 61(2):326-332. https://doi.org/10.1002/pbc.24556

18. Muller HL, Gebhardt U, Teske C, Faldum A, Zwiener I, Warmuth-Metz M, Pietsch T, Pohl F, Sorensen N, Calaminus G (2011) Study Committee of, K: Post-operative hypothalamic lesions and obesity in childhood craniopharyngioma: results of the multinational prospective trial KRANIOPHARYNGEOM 2000 after 3-year follow-up. Eur J Endocrinol 165(1):17-24. https://doi. org/10.1530/EJE-11-0158

19. Muller HL (2010) Increased daytime sleepiness in patients with childhood craniopharyngioma and hypothalamic tumor involvement: review of the literature and perspectives. Int J Endocrinol 2010:519607. https://doi.org/10.1155/2010/519607

20. Hargens TA, Kaleth AS, Edwards ES, Butner KL (2013) Association between sleep disorders, obesity, and exercise: a review. Nat Sci Sleep 5:27-35. https://doi.org/10.2147/NSS.S34838 
21. Fatima Y, Doi SA, Mamun AA (2015) Longitudinal impact of sleep on overweight and obesity in children and adolescents: a systematic review and bias-adjusted meta-analysis. Obes Rev 16(2):137-149. https://doi.org/10.1111/obr.12245

22. Hart CN, Cairns A, Jelalian E (2011) Sleep and obesity in children and adolescents. Pediatr Clin North Am 58(3):715-733. https:// doi.org/10.1016/j.pcl.2011.03.007

23. Jarrin DC, McGrath JJ, Drake CL (2013) Beyond sleep duration: distinct sleep dimensions are associated with obesity in children and adolescents. Int J Obes (Lond) 37(4):552-558. https://doi. org/10.1038/ijo.2013.4

24. Miller MA, Kruisbrink M, Wallace J, Ji C, Cappuccio FP (2018) Sleep duration and incidence of obesity in infants, children, and adolescents: a systematic review and meta-analysis of prospective studies. Sleep. https://doi.org/10.1093/sleep/zsy018

25. van Iersel L, Brokke KE, Adan RAH, Bulthuis LCM, van den Akker ELT, van Santen HM (2019) Pathophysiology and Individualized Treatment of Hypothalamic Obesity Following Craniopharyngioma and Other Suprasellar Tumors: A Systematic Review. Endocr Rev 40(1):193-235. https://doi.org/10.1210/ er.2018-00017

26. Muller HL, Bueb K, Bartels U, Roth C, Harz K, Graf N, Korinthenberg R, Bettendorf M, Kuhl J, Gutjahr P, Sorensen N, Calaminus G (2001) Obesity after childhood craniopharyngioma-German multicenter study on pre-operative risk factors and quality of life. Klin Padiatr 213(4):244-249. https://doi. org/10.1055/s-2001-16855

27. Moiseeva NI, Simonov MY, Sysuev VM (1978) The role of sleep in the regulation of circadian rhythms. Hum Physiol 4(6):799-805

28. Verberne LM, Maurice-Stam H, Grootenhuis MA, Van Santen HM, Schouten-Van Meeteren AY (2012) Sleep disorders in children after treatment for a CNS tumour. J Sleep Res 21(4):461469. https://doi.org/10.1111/j.1365-2869.2011.00971.x

29. Mandrell BN, Wise M, Schoumacher RA, Pritchard M, West N, Ness KK, Crabtree VM, Merchant TE, Morris B (2012) Excessive daytime sleepiness and sleep-disordered breathing disturbances in survivors of childhood central nervous system tumors. Pediatr Blood Cancer 58(5):746-751. https://doi.org/10.1002/pbc.23311

30. Narang I, Mathew JL (2012) Childhood obesity and obstructive sleep apnea. J Nutr Metab 2012:134202. https://doi. org/10.1155/2012/134202

31. Adachi M, Tsuchiya T, Muroya K, Asakura Y, Sekido K, Sato H (2007) Prevalence of obesity, hyperlipemia and insulin resistance in children with suprasellar brain tumors. Clin Pediatr Endocrinol 16(1):1-9. https://doi.org/10.1297/cpe.16.1

32. Arens R, Muzumdar H (2010) Childhood obesity and obstructive sleep apnea syndrome. J Appl Physiol 108(2):436-444. https:// doi.org/10.1152/japplphysiol.00689.2009

33. Harding SM (2000) Complications and consequences of obstructive sleep apnea. Curr Opin Pulm Med 6(6):485-489

34. Muller HL, Handwerker G, Gebhardt U, Faldum A, Emser A, Kolb $\mathrm{R}$, Sorensen N (2006) Melatonin treatment in obese patients with childhood craniopharyngioma and increased daytime sleepiness. Cancer Causes Control 17(4):583-589. https://doi.org/10.1007/ s10552-005-9012-7

35. Bruni O, Alonso-Alconada D, Besag F, Biran V, Braam W, Cortese S, Moavero R, Parisi P, Smits M, Van der Heijden K, Curatolo $P$ (2015) Current role of melatonin in pediatric neurology: clinical recommendations. Eur J Paediatr Neurol 19(2):122-133. https:// doi.org/10.1016/j.ejpn.2014.12.007
36. Andersen LP, Gogenur I, Rosenberg J, Reiter RJ (2016) The Safety of Melatonin in Humans. Clin Drug Investig 36(3):169-175. https ://doi.org/10.1007/s40261-015-0368-5

37. Saper CB, Fuller PM, Pedersen NP, Lu J, Scammell TE (2010) Sleep state switching. Neuron 68(6):1023-1042. https://doi. org/10.1016/j.neuron.2010.11.032

38. Autret A, Lucas B, Henry-Lebras F, de Toffol B (1994) Symptomatic narcolepsies. Sleep 17(8 Suppl):S21-24. https://doi. org/10.1093/sleep/17.suppl_8.s21

39. Weil AG, Muir K, Hukin J, Desautels A, Martel V, Perreault S (2018) Narcolepsy and Hypothalamic Region Tumors: Presentation and Evolution. Pediatr Neurol 84:27-31. https://doi. org/10.1016/j.pediatrneurol.2017.12.016

40. Littner MR, Kushida C, Wise M, Davila DG, Morgenthale T, LeeChiong T, Hirshkowitz M, Loube DL, Bailey D, Berry RB, Kapen S, Kramer M (2005) Practice Parameters for Clinical Use of the Multiple Sleep Latency Test and the Maintenance of Wakefulness Test. Sleep 28(1):113-121. https://doi.org/10.1093/sleep/28.1.113

41. Muller HL, Muller-Stover S, Gebhardt U, Kolb R, Sorensen N, Handwerker G (2006) Secondary narcolepsy may be a causative factor of increased daytime sleepiness in obese childhood craniopharyngioma patients. J Pediatr Endocrinol Metab 19(Suppl 1):423-429

42. Mason PW, Krawiecki N, Meacham LR (2002) The use of dextroamphetamine to treat obesity and hyperphagia in children treated for craniopharyngioma. Arch Pediatr Adolesc Med 156(9):887-892

43. Madhusoodanan S, Ting MB, Farah T, Ugur U (2015) Psychiatric aspects of brain tumors: a review. World J Psychiatr 5(3):273

44. Halbower AC, Marcus CL (2003) Sleep disorders in children. Curr Opin Pulm Med 9(6):471-476. https://doi.org/10.1097/00063198200311000-00004

45. El Shakankiry HM (2011) Sleep physiology and sleep disorders in childhood. Nat Sci Sleep 3:101-114. https://doi.org/10.2147/ NSS.S22839

46. Biddle SJ, Asare M (2011) Physical activity and mental health in children and adolescents: a review of reviews. Br J Sports Med 45(11):886-895. https://doi.org/10.1136/bjsports-2011-090185

47. Rosen G, Brand SR (2011) Sleep in children with cancer: case review of 70 children evaluated in a comprehensive pediatric sleep center. Support Care Cancer 19(7):985-994. https://doi. org/10.1007/s00520-010-0921-y

48. Mindell JA, Kuhn B, Lewin DS, Meltzer LJ, Sadeh A (2006) American Academy of Sleep, M Behavioral treatment of bedtime problems and night wakings in infants and young children. Sleep 29(10):1263-1276

49. Cain N, Gradisar M (2010) Electronic media use and sleep in school-aged children and adolescents: A review. Sleep Med 11(8):735-742. https://doi.org/10.1016/j.sleep.2010.02.006

50. Daniel LC, van Litsenburg RRL, Rogers VE, Zhou ES, Ellis SJ, Wakefield CE, Stremler R, Walter L, Crabtree VM, International Psycho-Oncology Society Pediatrics Special Interest, G (2019) A call to action for expanded sleep research in pediatric oncology: A position paper on behalf of the International Psycho-Oncology Society Pediatrics Special Interest Group. Psychooncology. https ://doi.org/10.1002/pon.5242

Publisher's Note Springer Nature remains neutral with regard to jurisdictional claims in published maps and institutional affiliations. 